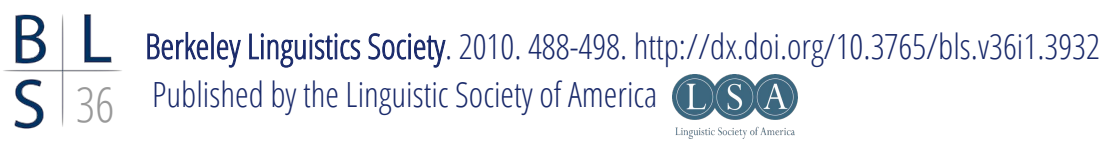

\title{
Perception of Illegal Contrasts: Japanese Adaptations of Korean Coda Obstruents ${ }^{1}$
}

\author{
JAMES D. Y. WHANG \\ New York University
}

\section{Introduction}

A series of studies by Dupoux and colleagues (Dupoux et al. (1999), Peperkamp \& Dupoux (2003), Vendelin \& Peperkamp (2004), Peperkamp (2005)) have proposed that loanword adaptation, which refers to the transformation words go through when they are borrowed from a source language (L2) to a borrowing language (L1), happens entirely during perception. They claim that when an L1 speaker is given an acoustic signal that contains segments that are illegal in his native language, his native phonotactics distort how this signal is perceived, automatically mapping it to the closest well-formed sound, and that this process, called perceptual assimilation, often makes it extremely difficult to perceive nonnative sounds accurately. This paper provides evidence partially contrary to their claims, from adaptations of Korean final coda obstruents into Japanese, showing that Japanese speakers are able to perceive some phonotactically illegal contrasts.

\section{Korean Loanwords in Japanese}

\subsection{Overview}

There has been an influx of Korean loans into Japanese since the turn of the $21 \mathrm{st}$ century, following a cultural trend in Japan called "the Korean Wave," where all things Korean gained tremendous popularity. The majority of Korean loanwords in Japanese are in the lexical category of cuisine, and it can be assumed that these

\footnotetext{
${ }^{1}$ Special thanks to Kie Zuraw for discussion and continued support. Also thanks to Kaori Furukawa for sharing her research results and to the audience members of BLS 36 for comments and feedback.
} 


\section{James D. Y. Whang}

loans are based more on auditory perception compared to western loans, as knowledge of Korean orthography is still relatively low in Japan. Evidence of this can be seen in numerous Japanese web forums where the users discuss the "correct" way to spell and pronounce Korean loans, many bringing up the issue of their own perception (website 1). Korean loans into Japanese, therefore, provide a rare look into the actual process of how words are borrowed with minimal orthographic interference.

\subsection{Data}

Japanese word structure is primarily CVCV, with only one obstruent coda $/ \mathrm{Q} /$, written as $\supset$ in hiragana or $ッ$ in katakana, which normally represents the first half of a geminate (Ito \& Mester 1995). Although it is not conventional orthographic practice to have a word end in $/ \mathrm{Q} /$, the characters representing it are actually used quite liberally in the word-final position in comic books and the like to indicate an abrupt pause in utterance, which surfaces in speech as a glottal stop.

$\begin{array}{lll}\text { (1) このつ } & \text { [kono?] } & \text { 'why, you...!' (literally, this) } \\ \text { 〈っ } & {[\text { ku?] }} & \text { 'a grunt' } \\ \text { 何ッ } & \text { [nani?] } & \text { 'what?! (emphatic)' }\end{array}$

The glottal stop, however, is optional and is not phonemic in its usage. ${ }^{2}$ By contrast, Korean allows [ $\left.\left.\mathrm{p}^{\urcorner}, \mathrm{t}\right\urcorner, \mathrm{k}^{\urcorner}\right]$in coda position (Sohn 1999:165), and as will be discussed later in this section, there are cases in which the three Korean final coda obstruents are mapped to the optional glottal stop in Japanese.

Data were obtained from Japanese websites, including personal blogs and professional sites dedicated to Korean culture, katakana transliterations of Korean pop song lyrics in Japanese karaoke machines, and two native Japanese speakerconsultants from Chiba (Kanto region) and Osaka (Kansai region). According to Japanese orthographic representations, Korean loanwords in Japanese behave similarly to the more well-documented western loans, showing deletion and epenthesis to resolve illegal codas.

(2) Deletion:

$\begin{array}{llll}{[\text { pibimpap }]} & > & {[\text { bibimba } \varnothing]} & \text { 'rice dish' } \\ {[\text { kukpap?] }} & > & {[\text { kuppa } \varnothing]} & \text { 'rice in soup' }\end{array}$

\footnotetext{
${ }^{2}$ There are native Japanese words that end in [?] (ちえつ [f̂je?] 'curse word'), but they are peripheral (Ito \& Mester 1995) and the necessity of the final $\supset$ seems to depend on the context.
} 


\section{Japanese Adaptations of Korean Coda Obstruents}

(3) Epenthesis:

\begin{tabular}{|c|c|c|c|}
\hline$\left[\mathrm{h}^{\mathrm{W}}\right.$ edoppap $\left.\urcorner\right]$ & $>$ & [фetoppapu] & 'rice mixed with raw fish' \\
\hline [k'ennip?] & $>$ & [kennipu] & 'sesame leaf' \\
\hline$\left[\mathrm{p}^{\mathrm{h}}\right.$ attfuk'] & $>$ & [patt̂uku] & 'red bean porridge' \\
\hline$\left[t^{\prime} \mathbf{o k} \mathbf{k}^{\top}\right]$ & $>$ & [tokku] & 'rice cake' \\
\hline
\end{tabular}

Currently, my data show that epenthesis is the most productive repair strategy for Korean coda obstruents, but as my analysis will show in the next section, it is unclear whether this epenthetic vowel is actually the result of acoustic perception or a misrepresentation due to limitations of Japanese orthography in expressing coda segments. Further research and experiment are required before any claims can be made, and thus epenthesis will not be discussed in too much detail in this paper. A new orthographic convention was found in the transliteration of Korean pop-song lyrics in Japanese karaoke machines, which also show epenthesis, but the kana characters that represent codas are written in subscript, presumably to show that the epenthesized vowel is "weak."
(4) $[\mathrm{ap}\urcorner]$ [maofimak?]
$>\quad\left[\mathrm{ap}_{\mathrm{u}}\right] \quad$ ア $\quad$ 'front' $>\quad\left[\operatorname{maffimak}_{\mathbf{u}}\right]$ マジマっ 'last'

There are no instances of epenthesis after [ $\left.\mathrm{t}^{\urcorner}\right]$. Instead, Japanese consistently resolves Korean final coda obstruent [ $\mathrm{t}\urcorner$ ] by means of debuccalization to a glottal stop, a repair strategy that can be seen with $[\mathrm{p}\urcorner, \mathrm{k}\urcorner]$ as well.

\begin{tabular}{|c|c|c|c|}
\hline [kimpap?] & $>$ & [kimpa?] & 'Korean style sushi roll' \\
\hline [tigit $\left.{ }^{7}\right]$ & $>$ & [tigu?] & 'Hangul letter t' \\
\hline [hot'ok $\urcorner]$ & $>$ & [hotto?] & 'grilled rice cake' \\
\hline
\end{tabular}

The repair strategies above often apply to the same words, resulting in multiple forms of the same words.

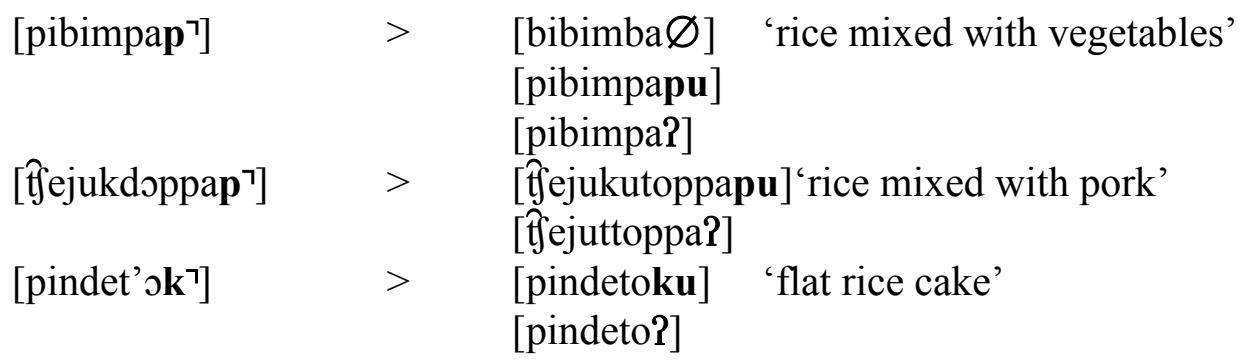


James D. Y. Whang

\subsection{Analysis}

Because all loanword adaptation occurs at the phonetic level during perception according to Peperkamp \& Dupoux (2003), there is no mapping from source pronunciation to nativized pronunciation that is regulated by L1 phonology, meaning the source is not treated as the underlying representation (UR). Rather, L1 phonology is involved in dictating how the acoustic input from L2 will be perceived. It is not surprising then that Japanese repairs Korean coda obstruents through deletion since Korean coda obstruents are strictly unreleased and thus acoustically similar to zero. On the other hand, what is surprising is that the two examples in (2), relisted below, were the only words that showed deletion.

$$
\begin{array}{llll}
{\left[\text { pibimpap` }^{\prime}\right]} & > & {[\mathrm{bibimba} \varnothing]} & \text { 'rice dish' } \\
\left.[\text { kukpap}\urcorner^{\prime}\right] & > & {[\operatorname{kuppa} \varnothing]} & \text { 'rice in soup' }
\end{array}
$$

All other loans show epenthesis or debuccalization, and while vowel epenthesis is by far the most productive repair strategy in Japanese for western loans, it is rather unexpected in the case of the unreleased Korean coda obstruents since epenthesis is usually an attempt to mimic release (Jun 2002). To confirm whether perceptual epenthesis actually occurs, I conducted a pilot perceptual experiment, where I recited five Korean words out loud twice and gave my two speaker consultants the task of repeating after me, then transcribing the words into katakana by hand. The results were as shown in (8) below. Romanized forms of the katakana transcriptions have been provided in parentheses.

\begin{tabular}{|c|c|c|c|c|}
\hline \multirow{3}{*}{$\begin{array}{l}\text { Stimulus } \\
{\left[\mathrm{t}^{\mathrm{h}} \text { ap }{ }^{\urcorner}\right]}\end{array}$} & \multirow{3}{*}{$>$} & \multirow{4}{*}{$\begin{array}{l}\text { Kanto } \\
\text { Speaker } \\
\text { [ta?], [tap?] } \\
\text { タッ, タフ } \\
\left(\operatorname{taQ}, \text { tap }_{\mathbf{u}}\right) \\
{[\operatorname{konnip}]} \\
\text { コンニ } \\
\left.\text { (konnip }_{\mathbf{u}}\right)\end{array}$} & \multirow{3}{*}{$\begin{array}{l}\text { Kansai } \\
\text { Speaker } \\
{[\text { ta?] }} \\
\text { タ } \\
(\operatorname{ta} \varnothing)\end{array}$} & \multirow{3}{*}{$\begin{array}{l}\text { Definition } \\
\text { 'tower' }\end{array}$} \\
\hline & & & & \\
\hline & & & & \\
\hline [k’onnip $\urcorner]$ & $>$ & & $\begin{array}{l}\text { [konni?] } \\
\text { コンニ } \\
\text { (konni } \varnothing)\end{array}$ & 'flower petal' \\
\hline [mat?] & $>$ & $\begin{array}{l}\text { [ma?] } \\
\text { マッ } \\
(\mathrm{maQ})\end{array}$ & $\begin{array}{l}{[\mathrm{ma} ?]} \\
₹ \\
(\mathrm{ma} \varnothing)\end{array}$ & 'flavor' \\
\hline$\left[\mathrm{mok}^{\mathrm{T}}\right]$ & $>$ & $\begin{array}{l}{[\mathrm{mo} ?]} \\
\text { モッ } \\
(\mathrm{moQ})\end{array}$ & $\begin{array}{l}{[\mathrm{mo} ?]} \\
\mp \\
(\mathrm{mo} \varnothing)\end{array}$ & 'neck' \\
\hline [sutkarak $\left.{ }^{\urcorner}\right]$ & $>$ & $\begin{array}{l}\text { [sukkara?] } \\
\text { スッカラッ } \\
\text { (sukkaraQ) }\end{array}$ & $\begin{array}{l}\text { [sukkara?] } \\
\text { スッカラ } \\
\text { (sukkara } \varnothing)\end{array}$ & 'spoon' \\
\hline
\end{tabular}




\section{Japanese Adaptations of Korean Coda Obstruents}

While the results above reveal that perceptual epenthesis does not occur after Korean final coda obstruents, they also reveal that the relationship between Japanese speech and orthography is somewhat unreliable when it comes to coda obstruents. First, notice that both consultants' speech show debuccalization for all of the words except the second, but the Kansai speaker's transcription shows deletion rather than debuccalization. I was surprised at the consistent discrepancy between the Kansai dialect speaker's speech and transcription and inquired her regarding the matter, but she stated that her transcriptions accurately represented what she heard, meaning the final glottal stop in her speech is non-contrastive. Second, the Kanto dialect speaker's transcription uses subscript kana to represent the coda $\left[\mathrm{p}^{\urcorner]}\right.$for the first two examples, showing that it represents an unreleased lip closure. However, when I asked the Kansai speaker about the subscript kana, she claimed that she would read it like a full-sized kana and that the smaller size of the kana is meaningful only in that it lets her know that the sound is "weaker" in Korean. So it seems that while subscript kana is an attempt to mimic the unreleased Korean coda obstruents, there still is no consensus on what the correct way to read it is. Given the experimental results above, I will assume that epenthetic vowels in Korean coda adaptations are not the result of a misperceived extra vowel, and thus will focus on debuccalization. In fact, the epenthesized forms are usually found in websites run by Korean individuals or companies, who may be basing their transcriptions on what they expect Japanese speakers to do.

Debuccalization, a process in which the supralaryngeal articulation of a consonant is lost, satisfies the Coda-Condition constraint in Japanese, which disallows place in coda (Kager 1999:131), by neutralizing the three Korean coda obstruents $[p\urcorner, t\urcorner, k\urcorner]$ to glottal stop.

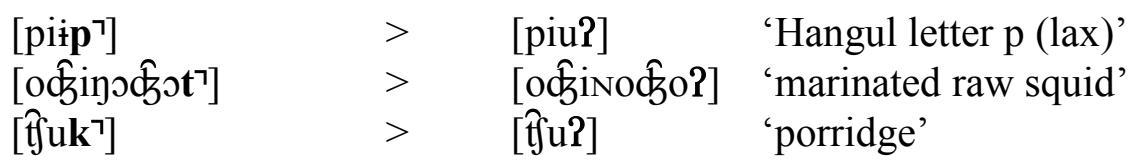

This process of debuccalization of Korean coda obstruents in Japanese shows that native Japanese speakers are able to perceive the presence of a final stop. A similar case of debuccalization can be seen in Bahasa Indonesia loans into Selayarese (Broselow 2002). However, unlike in Selayarese, word-final glottal stop is not a phoneme but an optional variant of $\varnothing$ in Japanese (Bloch 1950), and thus, this neutralization of $[\mathrm{p}\urcorner, \mathrm{t}\urcorner, \mathrm{k}\urcorner]$ to glottal stop, while it preserves the restriction against place contrast in coda, violates another restriction against a contrast between final glottal stop and final zero.

Peperkamp and Dupoux probably would not use Optimality Theory to support their arguments, but it is useful in illustrating the mechanism behind how things get perceived. Therefore, provided below are the constraints and their ranking from Furukawa (2009), which reflect how Korean coda obstruents are perceived 


\section{James D. Y. Whang}

in Japanese. I would like to clarify that the tableaux below do not represent the mapping from a lexical entry to a surface form, but rather a mapping from acoustic input to a perceptual representation based on Peperkamp \& Dupoux's (2003) argument that all loanword adaptation occurs during perception.

(10) Constraints

a. CODACOND *Place] $\sigma$. A coda may not have its own place feature (though it may share place features with a following onset)

b. IDENT-IO [Place]. Correspondent segments in input and output have identical values for their place of articulation

c. IDENT-IO [Release]. Correspondent segments in input and output have identical values for their release characteristics (i.e., whether they are audibly released or not)

d. MAX-IO. No deletion.

e. DEP-IO. No epenthesis.

(11) Korean input: pibimpap $\urcorner>$ bibimba $\varnothing$ or pibimpa? 'rice mixed with vegetables'

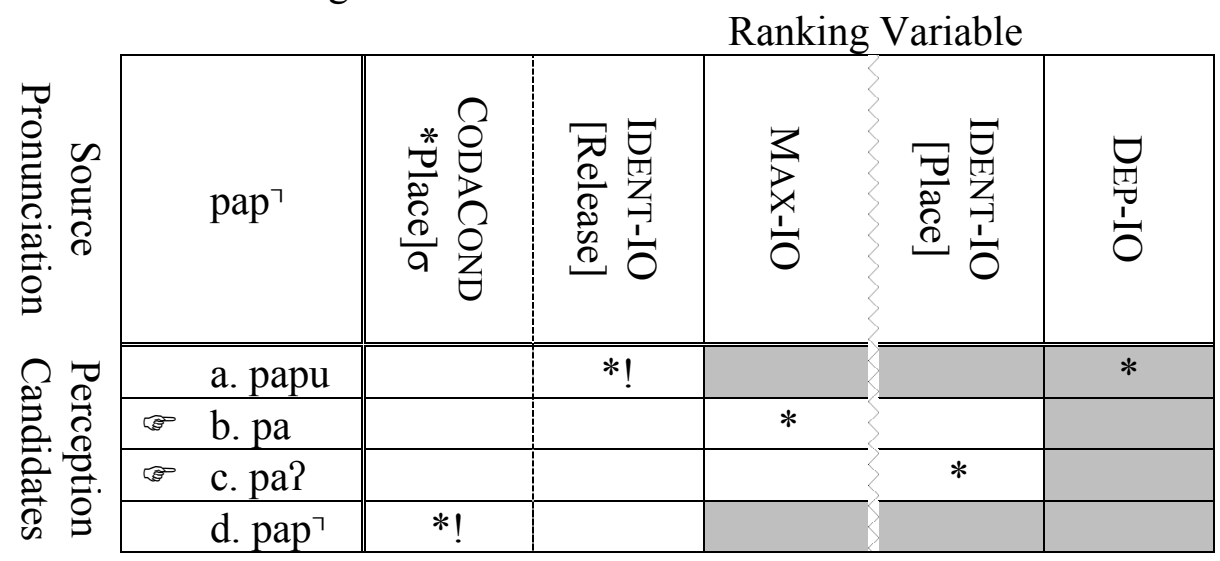

Compare (11) above to (12) below. 


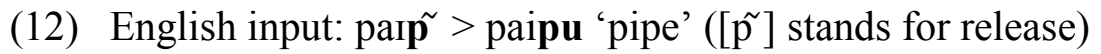

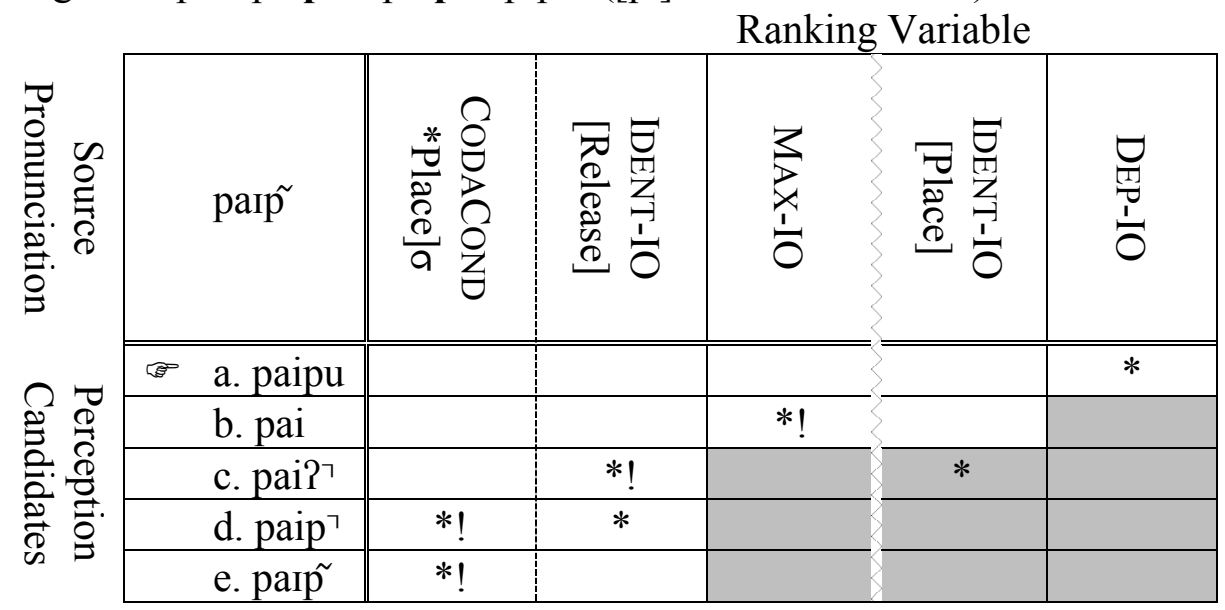

Furukawa's analysis shows that epenthesis is dispreferred for Korean loans because there is no release, which is not surprising since epenthesis is usually an attempt to preserve a misperceived release (Jun 2002). However because place contrast in codas is disallowed, native Japanese speakers are left to choose either deleting the consonant completely or deleting just the place features. A jagged line was used between MAX-IO and IDENT-IO [Place] because the ranking of the two seems to be variable depending on the speaker.

\section{Discussion}

Tableau (11) illustrates the idea that given an acoustic signal containing unreleased coda obstruents, it is equally possible for native Japanese speakers to perceive the phonotactically illegal segment as either non-existent or as a placeless coda. However, the distribution of deletion vs. debuccalization is extremely skewed, with only the two items in (2), listed again below, showing deletion.

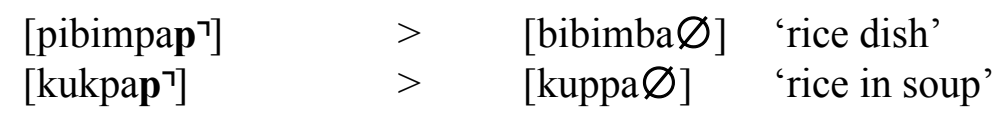

A possible explanation for this is that the two items above have been the all-timefavorite Korean dishes in Japan since before "the Korean Wave," when the knowledge of Korean phonology in Japan would have been extremely low. Early English loans into Japanese in the 19th and early 20th centuries had also undergone final coda deletion when borrowed under similar circumstances (Smith 2006). 
James D. Y. Whang

(14)

$$
\begin{aligned}
& \text { English } \\
& \text { pocket } \\
& \text { lemonade } \\
& \text { jitterbug }
\end{aligned}
$$

$\begin{array}{ll} & \text { 19th-20th Century Adaptation } \\ >\quad & {[\text { pokke } \varnothing]} \\ >\quad & {[\text { ramune } \varnothing]} \\ >\quad & {[\text { कुiruba } \varnothing]}\end{array}$

Since Japanese optionally inserts a glottal stop utterance-finally, it is quite possible that the final $\left[\mathrm{p}^{\urcorner}\right]$in the two examples in (13) completely deleted because it was perceived as a pause in utterance. All other loans were borrowed much more recently following the rise in popularity of all things Korean, and therefore, the borrowers would have had a higher level of proficiency in Korean and known that Korean allows coda obstruents word-finally. Of course, it is possible that the earlier loans in (13) were perceived with a glottal stop, but the fact that they did not explicitly note the presence of a coda segment orthographically suggests that the glottal stop was treated as non-contrastive. The more recent loans, however, do explicitly note the coda segments, meaning they are now treated as contrastive even though they are not contrastive in the native phonotactics. Evidence of this is the presence of pairs in which the final glottal stop becomes contrastive. In (15), $/ t^{\prime} \mathrm{ok} /$ is repaired by epenthesis, creating a minimal pair (the pitch-accents were identical for the Kansai speaker, though they differed for the Kanto speaker) with debuccalized /t'okkuk/:

$$
\begin{array}{llll}
\left.\left[\mathrm{t}^{\prime} \mathbf{k}^{\urcorner}\right\urcorner\right] & > & {[\text {tokku }]} & \text { 'rice cake' } \\
{\left[\mathrm{t}^{\prime} \mathrm{kkkuk}^{\prime}\right]} & > & {[\text { tokku? }]} & \text { 'rice cake soup' }
\end{array}
$$

The experience of my Kanto dialect speaker-consultant also seems to confirm a correlation between L2 proficiency and perceptual sensitivity toward phonotactically illegal segments, as she has been taking Korean language classes for a year and performed better than the Kansai dialect speaker in perceiving and noting the presence of the Korean coda obstruent. She claims that taking the classes has helped her to hear these segments she was once "deaf" to, although she admits that it is still difficult for her to distinguish among the three obstruents.

It is somewhat surprising that $\left[p^{\urcorner}\right]$is neutralized despite its visually apparent labial feature. Both of my speaker consultants neutralized [p $\urcorner$ ] to a glottal stop, although the Kanto dialect speaker corrected herself the second time. 
(16)

\begin{tabular}{|c|c|c|c|c|}
\hline \multirow{3}{*}{$\begin{array}{l}\text { Stimulus } \\
\left.\left[\mathrm{t}^{\mathrm{h}} \text { ap }\right\urcorner\right]\end{array}$} & \multirow[b]{2}{*}{$>$} & \multirow{3}{*}{$\begin{array}{l}\text { Kanto } \\
\text { Speaker } \\
{[\text { ta?], [tap?] }} \\
\text { タッ, タフ } \\
(\text { taQ, tap } \\
{[\text { konnip?] }}\end{array}$} & \multicolumn{2}{|l|}{ Kansai } \\
\hline & & & & $\begin{array}{l}\text { Definition } \\
\text { 'tower' }\end{array}$ \\
\hline & & & $\begin{array}{l}\text { タ } \\
(\operatorname{ta} \varnothing)\end{array}$ & \\
\hline [k'onnip ] & $>$ & $\begin{array}{l}\text { [konnip }] \text { ] } \\
\text { コンニ } \\
\left(\text { konnip }_{\mathbf{u}}\right)\end{array}$ & $\begin{array}{l}\text { [konni?] } \\
\text { コンニ } \\
\text { (konni } \varnothing)\end{array}$ & 'flower petal' \\
\hline
\end{tabular}

This may be due to the fact that lip closure occurs freely in the coda position in emphatic/firm speech in Japanese (/hai/ > [haip ?] 'yes', /ikimaseN/ > [ikimasem] 'not going'), and thus is not treated as contrastive.

Generally speaking, however, debuccalization of $\left[\mathrm{p}^{\urcorner}, \mathrm{t}^{\urcorner}, \mathrm{k}^{\urcorner}\right]$seems quite similar to how final $/ \mathrm{n} /$ of English and French loanwords are dealt with in Japanese. English / $\mathrm{n} /$ is mapped to the moraic nasal consonant of Japanese, which assimilates in place to a following consonant, or, if word-final, surfaces as a uvular nasal or just a nasalization of the preceding vowel. French $/ \mathrm{n} /$, on the other hand, is unnecessarily repaired as a geminate nasal followed by an epenthetic vowel (Vendelin \& Peperkamp 2004).

(17) From Vendelin \& Peperkamp 2004

$\begin{array}{lllll}{[\text { skri:n] }} & > & \text { [sukuri:N] } & \text { 'screen' } & \text { English } \\ {[\text { dwan }]} & > & {[\text { duannu }]} & \text { 'customs' } & \text { French }\end{array}$

Vendelin and Peperkamp attribute this difference in adaptation strategies to the differences in length and intensity of final [ $\mathrm{n}$ ] in both languages and their release. Phonetically, /N/ in Japanese is placeless in the same way glottal stop is, and if it is the case that English final $/ \mathrm{n} /$ is being mapped to the placeless $/ \mathrm{N} /$ because it is perceived to be weaker than French final $/ \mathrm{n} /$, then this could also mean that Korean coda obstruents are resolved through debuccalization rather than through epenthesis because Japanese speakers perceive the strictly unreleased coda obstruents of Korean to be weaker than the variably released English final coda obstruents.

\section{Conclusion}

Dupoux and his colleagues argue that all loanword adaptations occur during perception and that any structure that is phonotactically illegal in L1 is mapped to the closest legal native counterpart. However, this paper has shown an intermediate case with Korean loanwords in Japanese, where one illegal contrast fails to get perceived (place in the coda) while another illegal contrast that results from the first failure does get perceived (presence vs. absence of final stop, realized as 


\section{James D. Y. Whang}

glottal stop vs. zero), the latter of which was not perceived with older loans, as the orthography suggests. This development of sensitivity towards illegal contrasts can be linked to L2 proficiency, and my pilot perceptual experiment seems to support this. However, there may be other factors involved in my speakerconsultants' different levels of sensitivity towards Korean final coda obstruents, such as high vowel devoicing between voiceless segments, which is observed in the Kanto dialect but not in the Kansai dialect. Another possible explanation for the sensitivity toward illegal contrasts is that there is more direct exposure to Korean acoustic sources through various media outlets such as pop music, television shows, and movies; debuccalization may be evidence that the optional utterance-final glottal stop is becoming phonemic through this increased exposure.

The greatest shortcoming of this research, even with my two speaker consultants, is that my analysis is based heavily on the orthographic representations of Korean loanwords in Japanese, which is very limited in its ability to express coda segments, although there are new orthographic conventions that try to remedy this. A larger-scale perceptual experiment than what was presented in (8) should provide clearer insight into how Korean final coda obstruents are perceived in Japanese. Besides looking just at how native Japanese speakers from different dialectal regions with different levels of exposure to Korean perceive acoustic stimuli, an interesting experiment could be to test whether their perception changes based on whether they are told that the acoustic stimuli are Korean, English, or an artificial language.

This research also brought up some new questions, such as the environments in which glottal stop and lip closure surface. They both occur utterance finally, but it is unclear whether they are simply two different surface forms of $/ \mathrm{Q} /$ or they are to be treated separately. Thus far, it seems likely that glottal stop is the default and lip closure an allophone, but further research is required.

\section{References}

Bloch, Bernard. 1950. Studies in Colloquial Japanese IV Phonemics. Language 26: $86-125$.

Broselow, Ellen. 1999. Stress, Epenthesis, and Segment Transformation in Selayarese Loans. In S. Chang, L. Liaw, and J. Ruppenhofer, eds., Proceedings of the 25th Annual Meeting of the Berkeley Linguistic Society, 311-325.

Dupoux, E., K. Kakehi, Y. Hirose, C. Pallier, and J. Mehler. 1999. Epenthetic Vowels in Japanese: A Perceptual Illusion? Journal of Experimental Psychology: Human Perception and Performance 25: 1568-1578. 


\section{Japanese Adaptations of Korean Coda Obstruents}

Furukawa, Kaori. 2009. Perceptual Similarity in Loanword Adaptation Between Japanese and Korean. MA thesis, University of Toronto.

Ito, Junko, \& Armin Mester. 1995. The Phonological Lexicon. In N. Tsujimura, ed., The Handbook of Japanese Linguistics, 62-100. Oxford: Blackwell.

Jun, Eun. 2002. An Experimental Study of the Effect of Release of English Syllable Final Stops on Vowel Epenthesis in English Loanwords. Studies in Phonetics, Phonology and Morphology 8: 117-134. Seoul: Hankwukmunhwasa.

Kager, René. 1999. Optimality Theory. Cambridge: Cambridge University Press.

Peperkamp, Sharon and Emmanuel Dupoux. 2003. Reinterpreting Loanword Adaptations: The Role of Perception. International Congresses of Phonetic Sciences 15: 367-370.

Peperkamp, Sharon. 2004. A Psycholinguistic Theory of Loanword Adaptations. In M. Ettlinger, N. Fleisher, and M. Park-Doob, eds., Proceedings of the 30th Annual Meeting of the Berkeley Linguistic Society, 341-352.

Smith, Jennifer 2006. Loan Phonology is Not All Perception: Evidence from Japanese Loan Doublets. In T. J. Vance, ed., Japanese/Korean Linguistics 14: 63-74. Stanford, CA: CSLI.

Sohn, Ho-min. 1999. The Korean Language. Cambridge: Cambridge University Press.

Vendelin, Inga and Sharon Peperkamp. 2004. Evidence for Phonetic Adaptation of Loanwords: An Experimental Study. Actes des IVèmes Journées d'Etudes Linguistiques de l'Université de Nantes, 127-132.

Website 1. ピビンバ? ビビンバ?

http://salami.2ch.net/food/kako/992/992004337.html/ (October 30, 2009).

James Whang

New York University

Department of Linguistics

10 Washington Place

New York, NY 10003

james.whang@nyu.edu 